\title{
The Potential Risk of Carbon Dioxide Gas in Closed Areas in Faculty Places - Study Case
}

\author{
Mai M Al-Saadi*, Asaad A AlRiyami, Waleed M Alabri, Ibrahim A Alkharusi and Mazin A \\ AlBalushi
}

Department of Engineering, Al Musanna College of Technology, Oman

*Corresponding author: Mai M Al-Saadi, Faculty of Mechanical, Department of Engineering, Al Musanna College of Technology, Oman.

To Cite This Article: M M Al-Saadi*, A A AlRiyami, W M Alabri, I A Alkharusi, M A AlBalushi. The Potential Risk of Carbon Dioxide Gas in Closed Areas in Faculty Places - Study Case. Am J Biomed Sci \& Res. 2019 - 1(4). AJBSR.MS.ID.000534. DOI: 10.34297/AJBSR.2019.01.000534

Received: January 18, 2019 | Published: February 22, 2019

\section{Introduction}

Carbon dioxide gas is the main greenhouse which is coming from different sources like combustion of organic matter, fossil fuel and deforestation, ocean release etc. In addition, human being exhales $\mathrm{CO}_{2}$ during his respiration and the average human exhales about 2.3pounds of carbon dioxide on an average day [1]. The study was conducted in public faculty place where many students who used to come to the college in order to have their lessons in different majors. Therefore, there are sitting in different classrooms, library and canteen or roaming and walking between corridors. Three parameters were measured, and they are temperature and humidity and Concentration of Carbon dioxide in both units as \% \& ppm. The target of study was to correlate between concentration of $\mathrm{CO}_{2}$ and the presence of students at different locations with various times. Thus, the classrooms and crowed areas with human being started to become hotter and hotter with passing time and especially with less ventilation sources such as exhaust fans or fresh air exchanger system because of releasing of $\mathrm{CO}_{2}$ in second. As it is noticed the windows will be closed in order to make the rooms cooler and cooler but that will condense gases and settle down on the student' bodies. The below picture shows the reality of situation of students in their classrooms with less ventilation and closed windows during class session and it is same everywhere in the world (Picture 1).

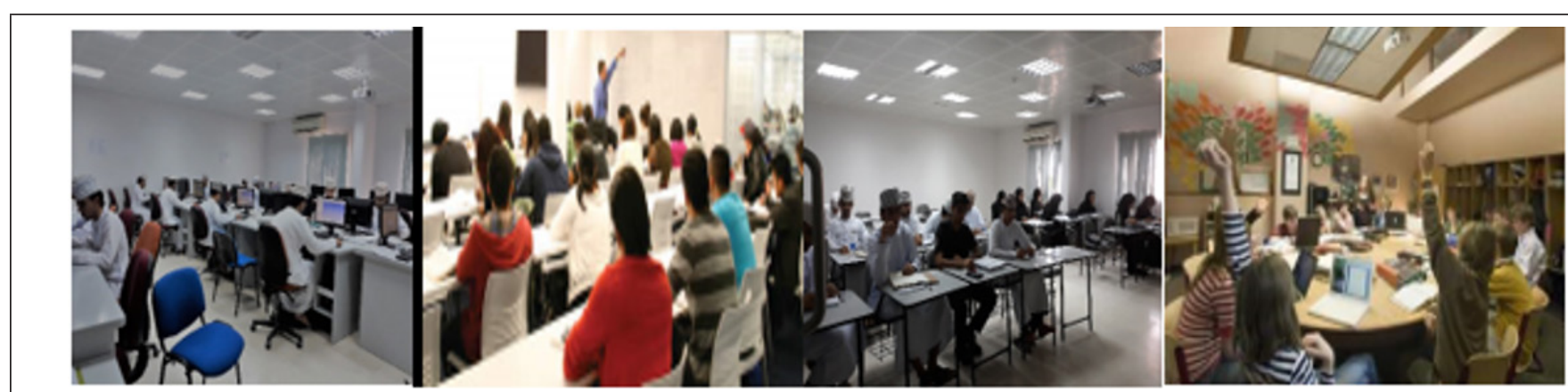

Picture 1: The Situation of students in their classes session with less ventilation system.

It is obvious how availability of accumulated carbon dioxide gas in upper layers of atmosphere could affect the climate and make different environmental issues, but it is necessary to explore to its potential effects on closed areas like vehicles, offices, classrooms, halls, and libraries because most of these places have less ventilation systems. Definitely, it is noticed that there are some side effects on human being' body especially if they are staying for long time in same place without air exchanger system. First, some of sickness like Feeling lazy, headache, Difficulty breathing, coughing, Lack of concentration and all these symptoms can start to appear because of declination in Oxygen level and increment of $\mathrm{CO}_{2}$ in those areas. Many students and workers cannot spend more than two hours in their classes or offices without having movement. Also many demised cases had been reported in cars due to heart attack or Choking and pain in feet especially at the night during sleeping in bedroom or even though in cars or buses with travelling for long distances which will take around nine hours and more than that like travelling in airplane. It is right there are safe levels of $\mathrm{CO}_{2}$ 
concentration in rooms which could let people to feel comfort, but they are not enough aware about precautions which need to be taken in case high level of gas reaches.
The Table 1 shows safe levels of $\mathrm{CO}_{2}$ in rooms, so it is recommended to install Monitor device in order to observe $\mathrm{CO}_{2}$ concentration in closed places Which may have a poor ventilation system (Table 1).

Table 1: The Safe level of $\mathrm{CO}_{2}$ concentration (ppm) in rooms. ${ }^{(2)}$

\begin{tabular}{|c|c|}
\hline Concentration $\mathbf{C O}_{\mathbf{2}} \mathbf{( p p m )}$ & Potential effects \\
\hline $250-350 \mathrm{ppm}$ & Normal background concentration in outdoor ambient air \\
\hline $350-1,000 \mathrm{ppm}$ & Concentrations typical of occupied indoor spaces with good air exchange \\
\hline $1,000-2,000 \mathrm{ppm}$ & Complaints of drowsiness and poor air. \\
\hline $2,000-5,000 \mathrm{ppm}$ & $\begin{array}{c}\text { Headaches, sleepiness and stagnant, stale, stuffy air. Poor concentration, loss of attention, increased heart rate and slight } \\
\text { nausea may also be present. }\end{array}$ \\
\hline $5,000 \mathrm{ppm}$ & Workplace exposure limit (as 8-hour TWA) in most jurisdictions. \\
\hline$>40,000 \mathrm{ppm}$ & Exposure may lead to serious oxygen deprivation resulting in permanent brain damage, coma, even death. \\
\hline
\end{tabular}

There are some studies which had reported that, the indoor concentration of Carbon dioxide in classroom needs to be below $700 \mathrm{ppm}$. From point of view, it is devisable because as normal outdoor concentration with 400ppm, so it supposes to be closer or little more. Because people absorb the gas by different other ways, injection though skin or mouth.

\section{Collection of Data}

Two devices were used to measure the concentration of $\mathrm{CO}_{2}$ at different locations over the college. The names of devices are Gas detector (PGas-21- $\mathrm{CO}_{2}$ ) and Globe instrument (P Gas-41). The readings were recorded at different times in different places in campus for short period.

Table 2: The concentration of $\mathrm{CO}_{2} \mathrm{ppm}$ at different locations.

\begin{tabular}{|c|c|c|c|c|c|}
\hline S.N & $\begin{array}{l}\mathrm{CO} 2 \\
\mathrm{ppm}\end{array}$ & $\begin{array}{l}\text { Temperature } \\
\mathrm{C}^{\circ}\end{array}$ & Humidity & Time & Location \\
\hline 1 & 779 & 31 & 30 & $1: 46 \mathrm{pm}$ & IT202 \\
\hline 2 & 774 & 23 & 35 & 1:10pm & ME 103 \\
\hline 3 & 774 & 25 & 33 & $1: 25 \mathrm{pm}$ & BS109 \\
\hline 4 & 773 & 25 & 33 & 4:00pm & ME 216 \\
\hline 5 & 773 & 31 & 32 & $1: 46 \mathrm{pm}$ & ELC \\
\hline 6 & 772 & 21 & 25 & 10:39am & ME215 \\
\hline 7 & 772 & 21 & 35 & $1: 03 \mathrm{pm}$ & ME215 \\
\hline 8 & 772 & 23 & 34 & 1:09pm & ME211 \\
\hline 9 & 772 & 24 & 34 & 1:15pm & elevator \\
\hline 10 & 772 & 24 & 34 & $1: 27 \mathrm{pm}$ & BS Passage \\
\hline 11 & 770 & 30 & 32 & $1: 00 \mathrm{pm}$ & ME PARKING \\
\hline 12 & 769 & 35 & NR & $2: 56 \mathrm{pm}$ & ME215 \\
\hline 13 & 769 & 25 & 33 & 11:55am & ME209 \\
\hline 14 & 769 & 26 & 33 & $12: 50 \mathrm{pm}$ & ME107 \\
\hline 15 & 769 & 33 & 33 & $2: 00 \mathrm{pm}$ & ME216 \\
\hline 16 & 769 & 28 & 34 & $1: 21 \mathrm{pm}$ & BS111 \\
\hline 17 & 769 & 28 & 32 & 1:41pm & Eel206 \\
\hline 18 & 769 & 27 & 33 & $2: 00 \mathrm{pm}$ & EL204 \\
\hline 19 & 767 & 23 & 30 & 3:00pm & ME 215 \\
\hline 20 & 767 & 31 & 31 & $1: 55 \mathrm{pm}$ & SAC \\
\hline 21 & 767 & 27 & 33 & 11:30am & ME215 \\
\hline 22 & 767 & 25 & 34 & $1: 43 \mathrm{pm}$ & IT201 \\
\hline 23 & 765 & 27 & 33 & $1: 53 \mathrm{pm}$ & IT208 \\
\hline 24 & 764 & 23 & NR & 9:09pm & ME214 \\
\hline 25 & 764 & 25 & 33 & $12: 40 \mathrm{am}$ & ME209 \\
\hline 26 & 764 & 26 & 33 & 1:58pm & IT303 \\
\hline 27 & 763 & 24 & 34 & 10:51am & ME115 \\
\hline 28 & 762 & 25 & NR & $10: 48 \mathrm{am}$ & ME115 \\
\hline 29 & 762 & 24 & 33 & $2: 00 \mathrm{pm}$ & ME216 \\
\hline 30 & 762 & 22 & 35 & 1:40pm & IT 203 \\
\hline
\end{tabular}


In order to see the variation in concentration of $\mathrm{CO}_{2}$ so Table 2 shows the concentration of $\mathrm{CO}_{2}$ gas was in range between 762-779 ppm and most readings were in afternoon time.

Factors need to be considered in order to get more realistic facts about the concentration of carbon dioxide. Constant installation for devices for longer time and it needs to be connected to software system for immediately analysis. Also, it supposes not to be random but specified location needed to study as wise as possible [2].

Many trials need to be conducted in order to confess the reasons behind increment of $\mathrm{CO}_{2}$ in some places but definitely the main reason is the presence of many of student in same time at same place that leads to record high concentration for $\mathrm{CO}_{2}$ gas.

\section{Results}

Both graphs showed there was increment in concentration of $\mathrm{CO}_{2}$ in most place during different afternoon and morning time The readings were in range as it has been reported in Table 1 so that means there good ventilation system such as presence of windows could help in releasing some of gas particulates (Table 3).

Table 3: The concentration of $\mathrm{CO}_{2} \mathrm{ppm}$ at different locations and times.

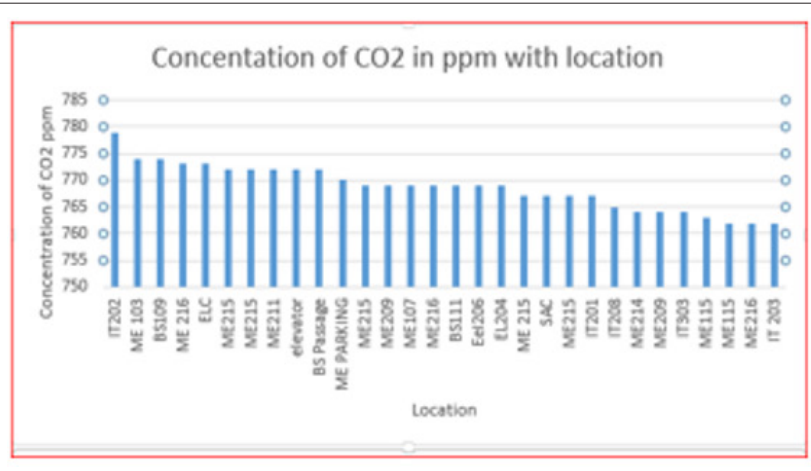

\section{Conclusion}

As the number of students is increasing in such place, that will lead to increase the concentration of Carbon dioxide which could affect the atmosphere of the class and make it hotter, then most of students are losing their interest and caution to their classes but

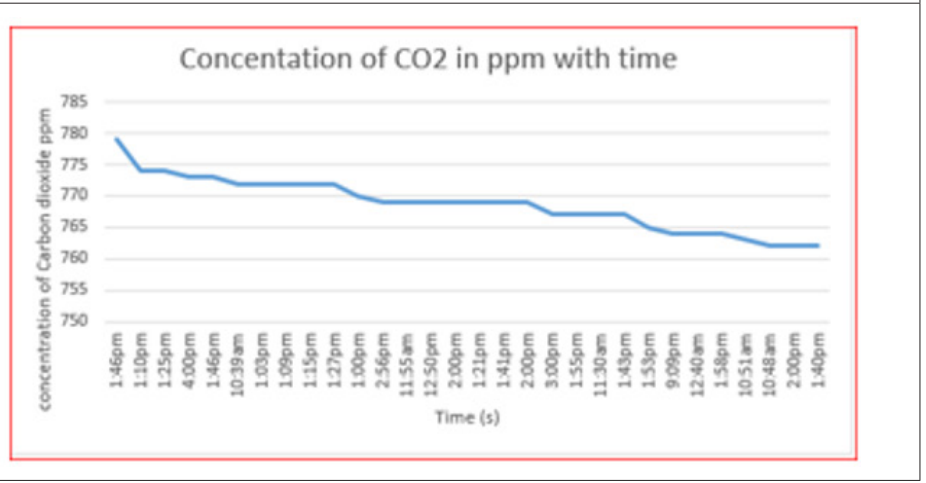

it can be managed by good ventilation system which will help to maintain the refreshment in the classroom.

\section{References}

1. Rate of $\mathrm{CO}_{2}$ as exhaling from Human Being.

2. What are safe levels of $\mathrm{CO}$ and $\mathrm{CO}_{2}$ in rooms? 